\title{
THE IMPACT OF HEAT GAIN SCHEDULES ON SUMMER OVERHEATING IN TYPICAL INSULATED DWELLINGS
}

\author{
R. PONECHAL ${ }^{*}$ D. JURASOVÁ \\ Faculty of Civil Engineering, University of Zilina, Univerzitna 8215/1., 01026 Zilina, Slovakia \\ *E-mail: radoslav.ponechal@fstav.uniza.sk
}

\begin{abstract}
Summer overheating is usually caused by a combination of factors, such as building location, orientation, fabric, ventilation and occupancy behaviour. People by their behaviour influence overheating through the internal heat gain mode and window opening ventilation mode. The article describes several types of occupancy profiles according to their behaviour taken from the literature: the profile of the worker, the child, the pensioner and the adventurer. From them, it is possible to disable the heat gain schedule for the whole household or apartment house. Heat gains from appliances are updated according to the modern lifestyle and current household appliances. The effect of heat gains in combination with other factors, which caused overheating, is further evaluated through the building simulation program.
\end{abstract}

Keywords: insulated dwellings, heat gain, occupancy, overheating, simulation

\section{Introduction}

Nothing is constant inside a building. People come and go, lights and equipment get turned on and off, etc. and the thermal simulation needs details on what is happening through the day and through the year within a building. Behaviour of users in a building can be defined in simulation in two principle ways. The first approach assumes that people will behave according to the chosen "standard" scheme. Standard schemes are made by the user according to standardized values adapted by his own decision. In studies of Bielek [1] and Hraska [2] the impact of building structures on summer overheating in Slovakia is studied. The effect of heat gains schedule itself is studied in United Kingdom by Tuohy [3].

In particular, it is common to use zero-occupancy schemes or maximum occupancy schemes. This creates the possibility to verify the behaviour of the building in both extreme scenarios. In addition to extreme conditions, the future user of the building will be interested in the fact how the building will run during normal (standard) operation. Here is the place for the second method of creating schedules based on statistical models.
The second approach is different and derives schedules from statistical observation. It also contains slightly "irrational" behaviour and is thus closer to the representation of reality. Those models have a higher level of reliability. Thanks to advances in microprocessor and sensor technology, there is a great boom in this area. Several research teams are currently focusing on creating such models [4-7]. Monitoring electrical demand of households is most important primarily for the adaptation of renewable energy sources, but it gives a good overview of the internal gains [8-12].

Although we have statistical data, there are still some questions. Some details make more sense especially by evaluating thermal comfort. For example the internal heat gains schedule, extracted from statistics, can be applied to all rooms in the building uniformly, or each room can have assigned its own schedule. Moreover rooms in dwelling may be connected or must not be connected by opened doors. Some days of the week are different (especially weekend). There are several types of users according to their behaviour. The effect of different heat gain schedule forms on summer overheating results is described in detail below.

This is an open-access article distributed under the terms of the Creative Commons Attribution-NonCommercial 4.0 International License (https://creativecommons.org/licenses/by-nc/4.0/), which permits unrestricted use, distribution, and reproduction in any medium for non-commercial purposes, provided the original author and source are credited, a link to the CC License is provided, and changes - if any - are indicated. 


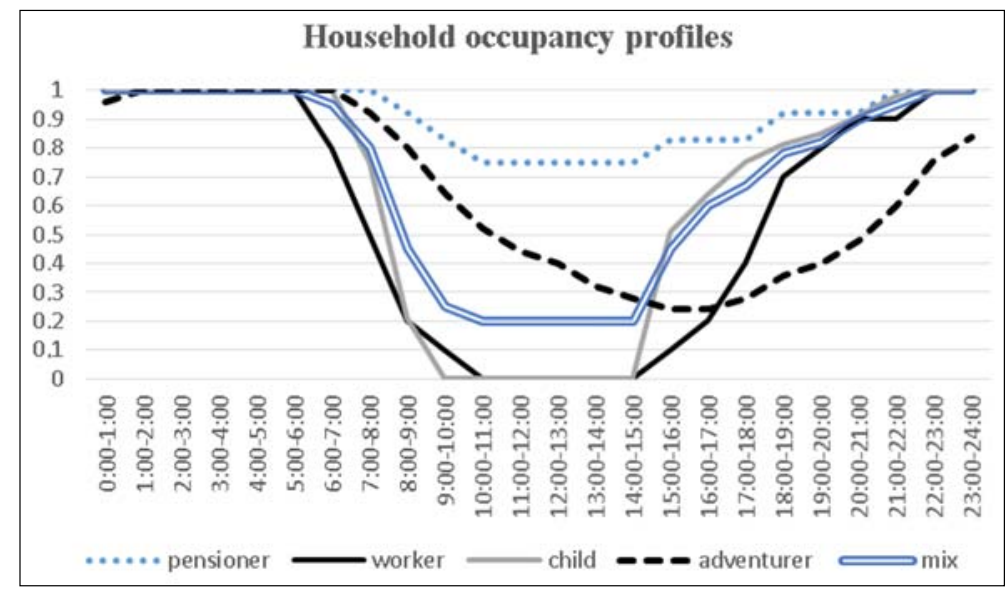

Fig. 1. Occupancy profiles created by Ref. [4]

\section{Materials and calculation methods}

The impact of heat gain schedules on summer overheating was tested with EnegyPlus numerical simulation software on model of typical dwelling. The T06B panel system is the most common system for Slovak apartment houses built up to the 1970s. Figure 1 shows a model of simulated storey. The surroundings of the monitored apartment was also simulated due to the right adjacent conditions. The perimeter walls as building envelope structures are made of a $300 \mathrm{~mm}$ thick lightweight concrete slab and a double-glazed plastic profile window. The inner walls are made of reinforced concrete with a thickness of $150 \mathrm{~mm}$, bars with a thickness of $80 \mathrm{~mm}$. The ceiling structure consists of a reinforced concrete panel with a thickness of

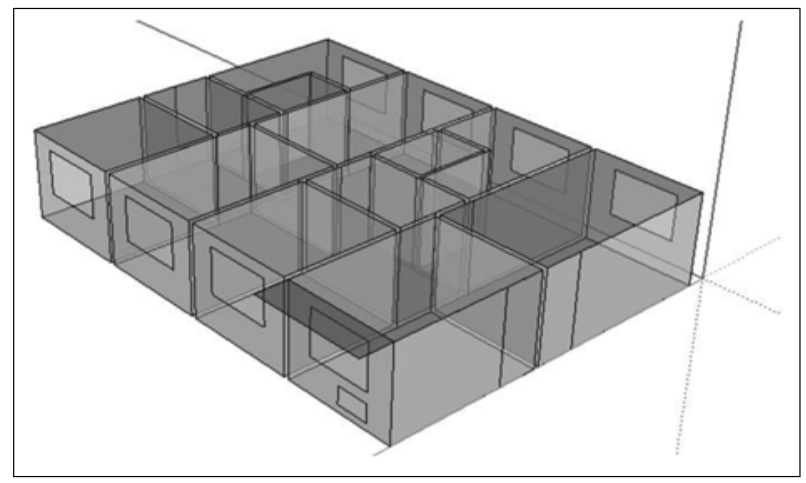

Fig. 2. Model of simulated storey
$120 \mathrm{~mm}$. The floor structure consists of foam polystyrene of $15 \mathrm{~mm}$ thickness, $38 \mathrm{~mm}$ concrete layer under the PVC flooring.

The assessment of the highest daily room temperature in the summer period was performed for northsouth and east-west facade orientation and for several building shields, expressed by shading an infinitely long barrier with $25^{\circ}$ equivalent angle. An indoor shading model of internal blinds with $50 \%$ solar transmission was applied to the windows. Window ventilation was simulated using an air exchange number. This was set to 1.0 times per hour for air exchange during the day, while in the morning and in the evening it increased to 4.0 times per hour. At night the air exchange was set to 2.0 times per hour.

Some answers to the questions asked in the introduction were researched through simulated alternatives with alternative schedules and other topics. These alternatives are described in Table 1.

\section{Results}

The graphs (Fig. 3) below shows the average temperature of the indoor air for each simulation alternative. When the graphs are compared visually, it is possible to get a notion of individual differences.

From a comparison of Figs 3 and 4 it follows that the simulation model with zone air mixing through open doors reduce the differences in air temperature. For example, warm air from the kitchen is mixed with

Table 1. Simulated alternatives

\begin{tabular}{llll}
\hline A1 & uniform heat gains are applied per $\mathrm{m}^{2}$ of room space & without zone mixing & mixed inhabitants \\
A2 & uniform heat gains are applied per $\mathrm{m}^{2}$ of room space & zone mixing & mixed inhabitants \\
A3 & each zone (room) has its own internal gains schedule & without zone mixing & mixed inhabitants \\
B1 & uniform heat gains are applied per $\mathrm{m}^{2}$ of room space & without zone mixing & mostly working people \\
B2 & uniform heat gains are applied per $\mathrm{m}^{2}$ of room space & without zone mixing & mostly retired people \\
\hline
\end{tabular}




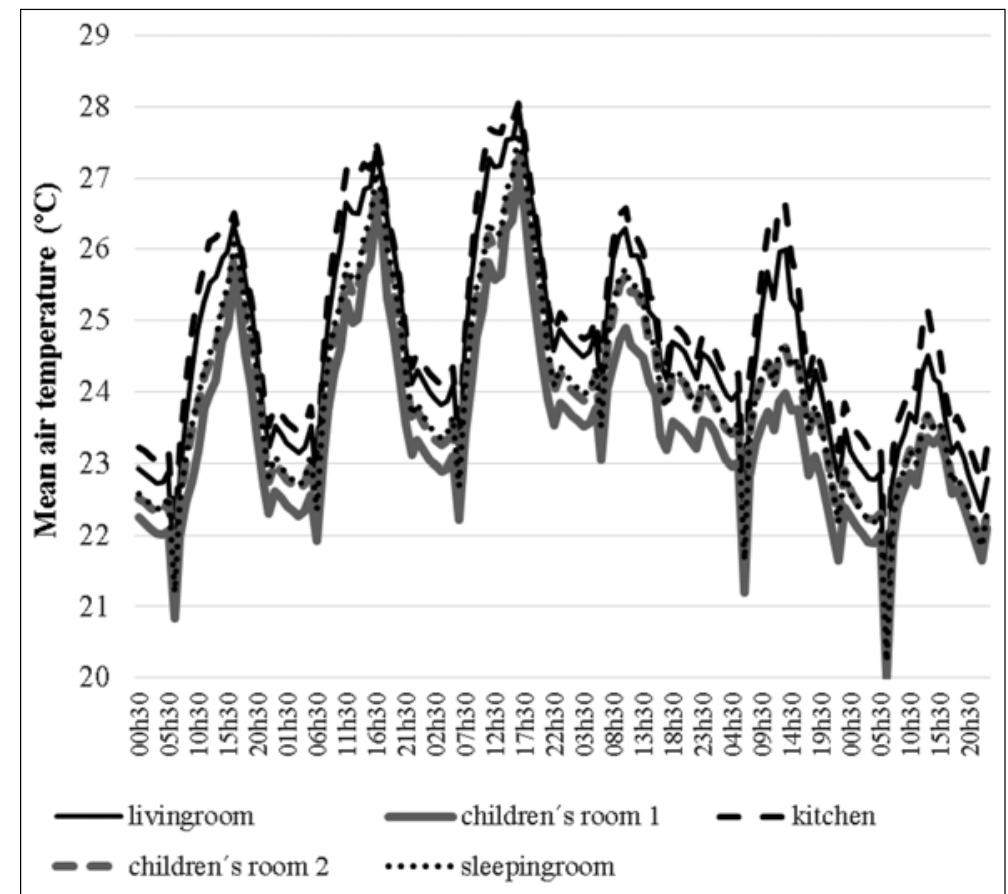

Fig. 3. Mean air temperature simulation results in summer in dwelling without zone mixing, uniform heat gains are applied per $\mathrm{m}^{2}$ of room space, the dwelling is inhabited with mixed inhabitants

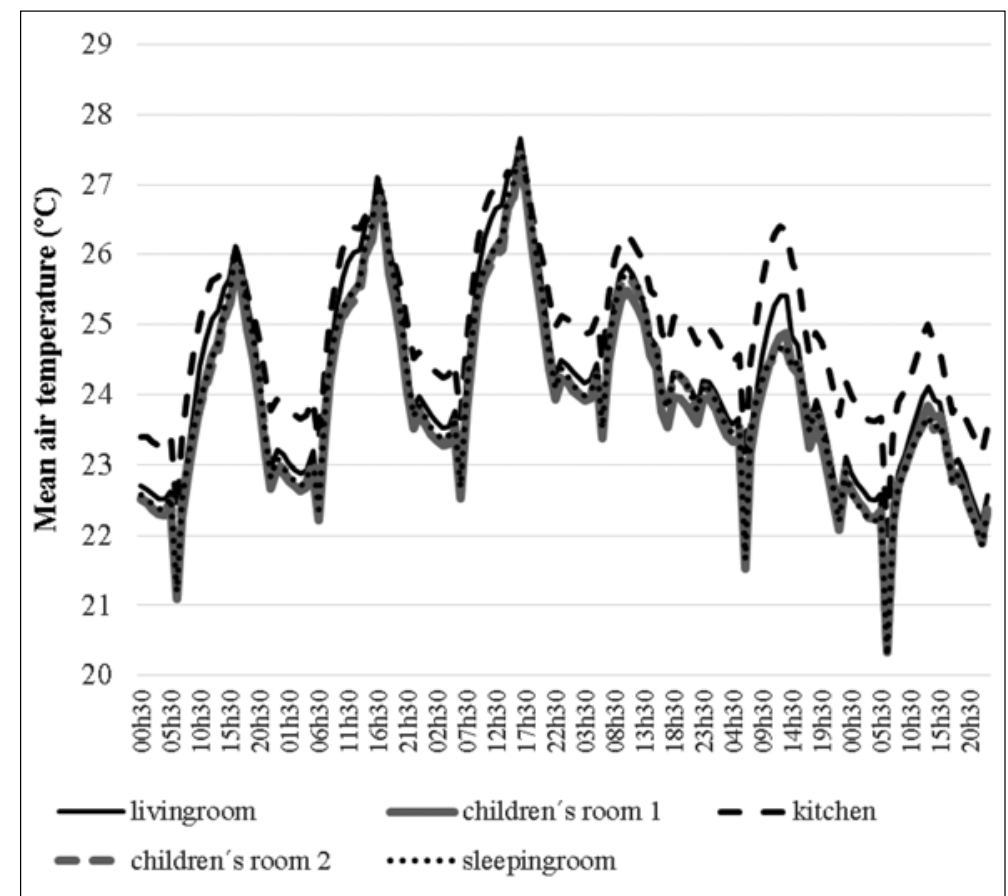

Fig. 4. Mean air temperature simulation results in summer in dwelling with zone mixing, uniform heat gains are applied per $\mathrm{m}^{2}$ of room space, the dwelling is inhabited with mixed inhabitants

cooler air from the bedroom. The heat gain is distributed throughout the whole apartment. Then the maximum air temperature is quite the same in all rooms.

If each room has its own internal gain schedule, the graph of air temperature (Fig. 6) will not change much, only the maximum values in the most crowded rooms (kitchen and living room) will increase.
Graphs of air temperature from simulations with different type of users (working and retired) (Figs 7 and 8) differ greatly and there is a difference over lunch time more than at the peak time in the afternoon. The air temperature less decreases afterwards in apartment with retired users. There is a difference of 2 degrees at night. This is probably caused by the more 


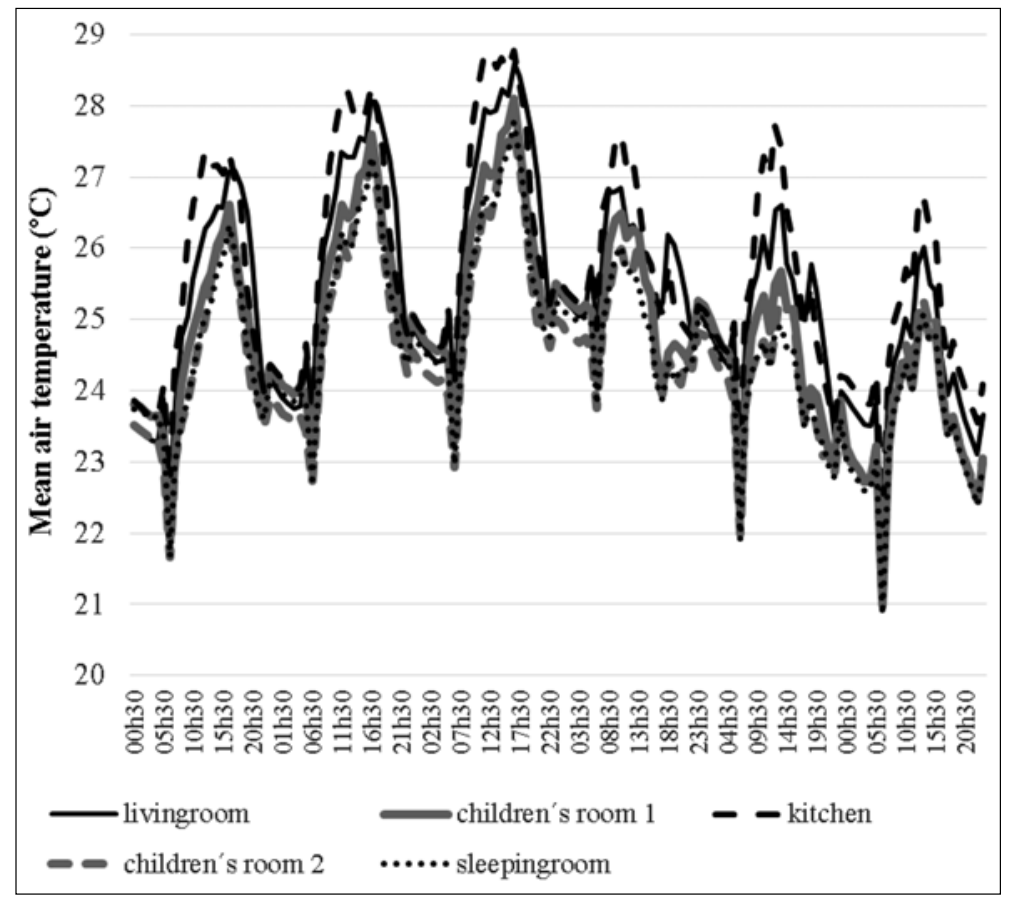

Fig. 5. Mean air temperature simulation results in summer in dwelling without zone mixing, each zone has its own internal gains schedule, the dwelling is inhabited with mixed inhabitants

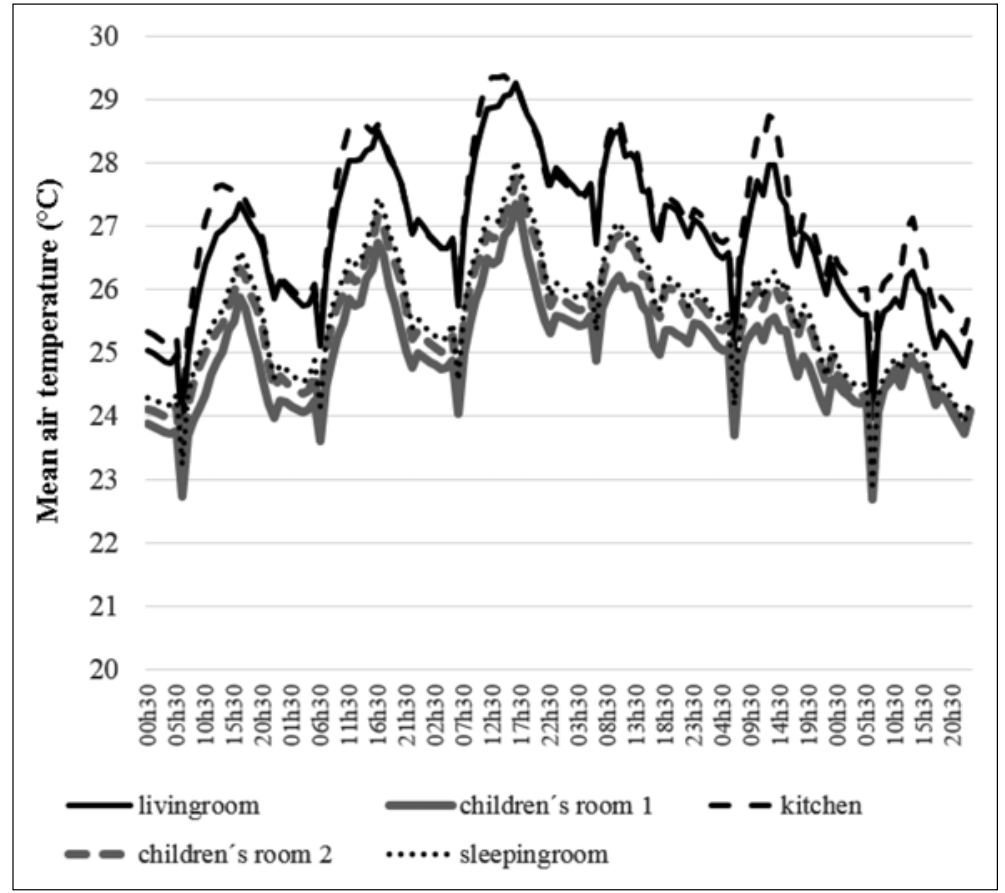

Fig. 6. Mean air temperature simulation results in summer in dwelling without zone mixing, uniform heat gains are applied per $\mathrm{m}^{2}$ of the floor area, the dwelling is inhabited mostly by working people

heated internal constructions due to the heat accumulation in them.

\section{Discussion}

The aim of the study is to highlight the impact of various internal heat gain models on summer overheating.
It turns out to be interesting. It is a difference whether internal gains are made throughout the day or only occasionally during the day. The obtained results are difficult to compare with other studies, because the problem of overheating is closely linked with other factors, such as building location, orientation, fabric, ventilation, etc. For example, Tuohy [3] has reached a 


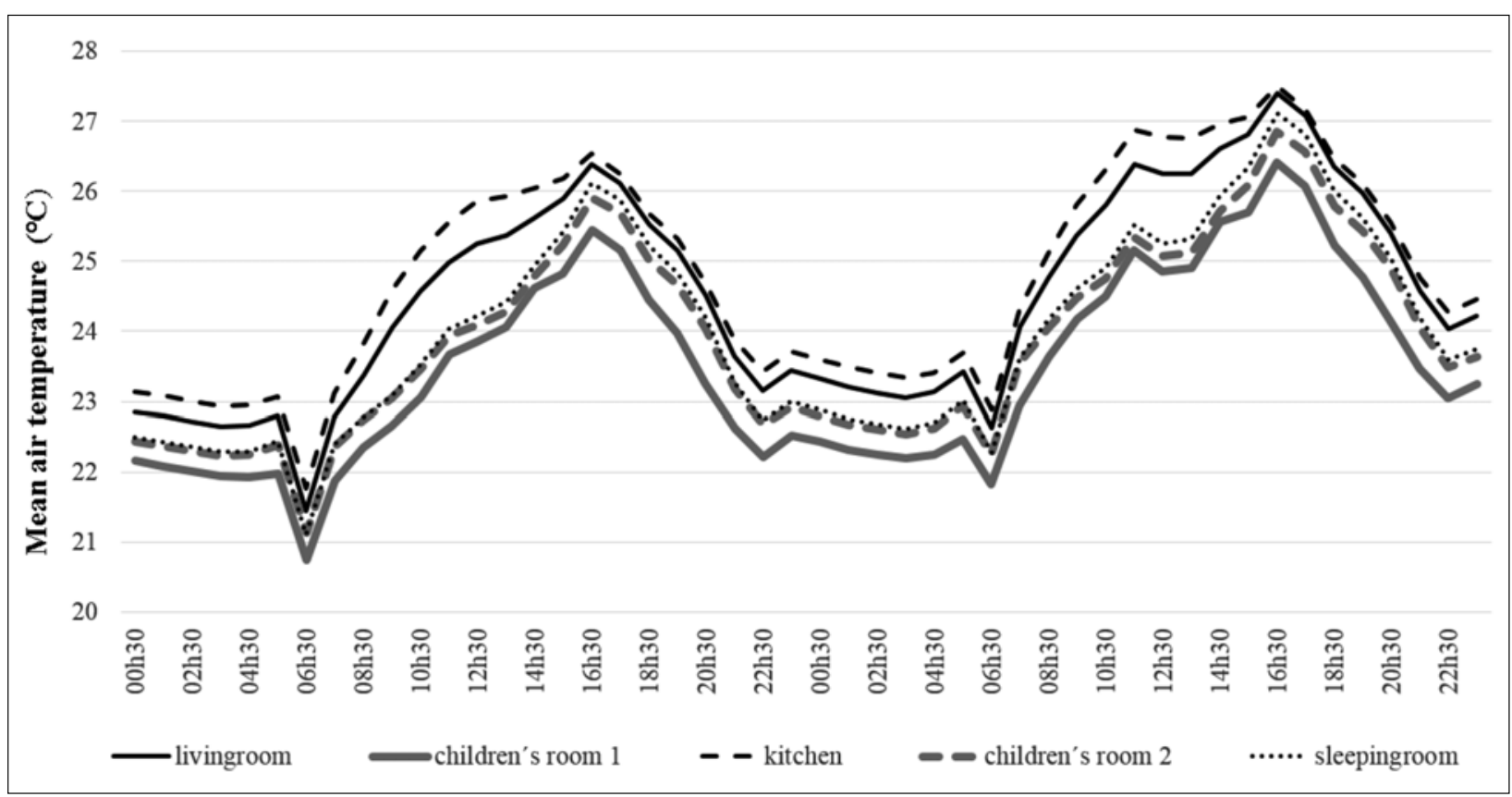

Fig. 7. Mean air temperature simulation results in summer in dwelling without zone mixing, uniform heat gains are applied per $\mathrm{m}^{2}$ of the floor area, the dwelling is inhabited mostly by working people

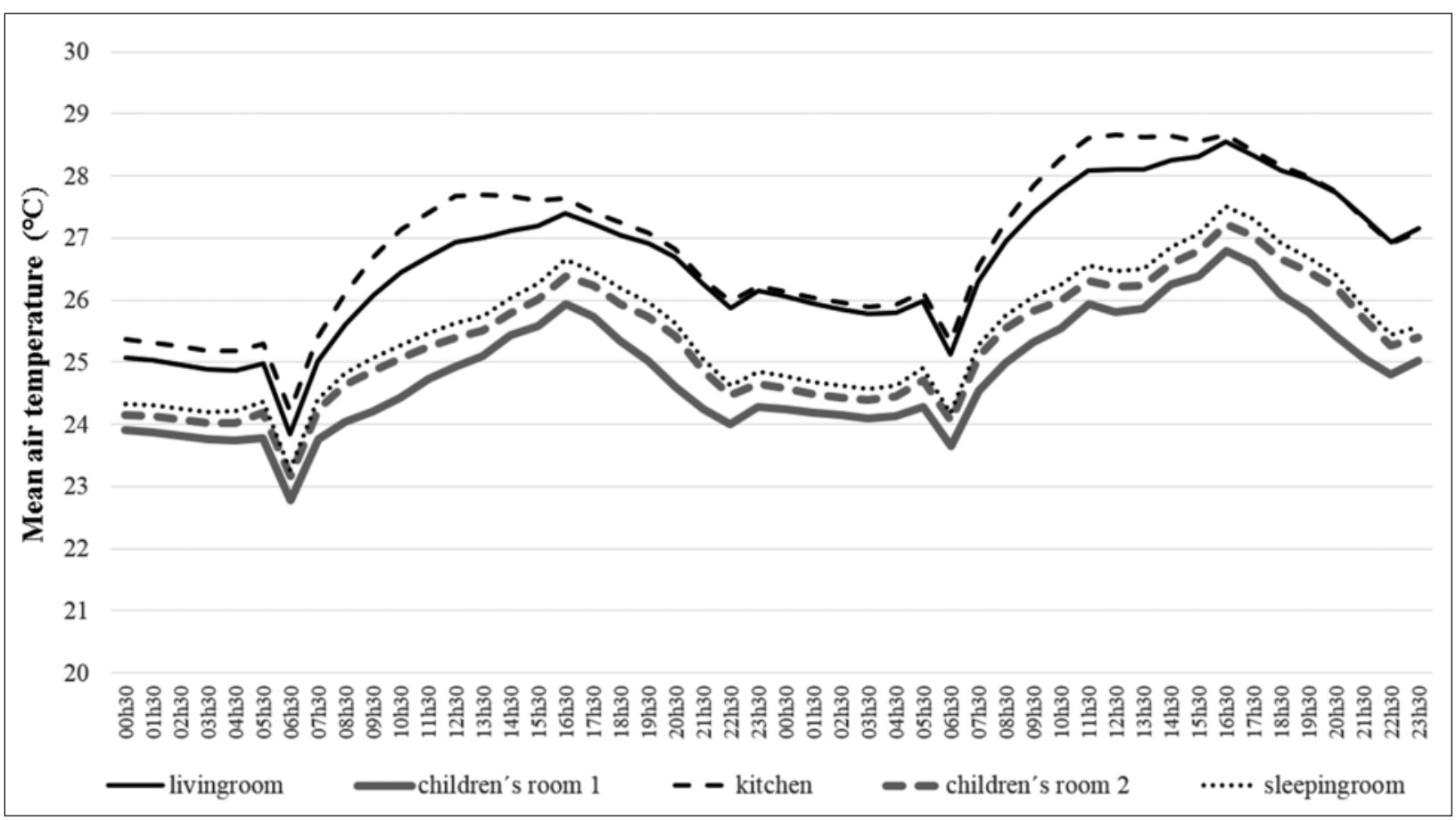

Fig. 8. Mean air temperature simulation results in summer in dwelling without zone mixing, uniform heat gains are applied per $\mathrm{m}^{2}$ of the floor area, the dwelling is inhabited mostly by retired people

difference of $1.0^{\circ} \mathrm{C}$ between the standard and high internal heat gains in model of lightweight building. In the building made of heavy materials the difference was even smaller. All this was done with intense ventilation $\left(4.5 \mathrm{~h}^{-1}\right)$.

Similarly, differences in results that compare simulations when each zone has its own internal gains schedule and the uniform heat gains are applied per $\mathrm{m}^{2}$ of floor area are not big. Those curves are quite similar. But a certain difference in curves is when considering air mixing between rooms through the opened doors. Here the difference in air temperature between the rooms in dwelling decreases. This goes especially for a bedroom with a children's room. 


\section{Conclusion}

The particular type of occupancy profile (according to people behaviour) used in thermal comfort simulation affect the results, the mean air temperature especially. In this study, only the consequences of the passive presence of individuals in the form of increased heat gains are addressed. But people affect by their presence in room (building) also the schedule of ventilation, lighting gains, setting of blinds, etc. In the future, a study should be developed in this direction, as it is processed in [13].

\section{Acknowledgements}

The research is supported by the grant project VEGA No. 1/0945/16.

\section{References}

[1] Bielek M. (1995), Building and Energy. In Slovak. Vidas, Banska Bystrica, Slovakia. p. 43.

[2] Hraska J. (2004), Simulation of building interactions and thermal balance of model room. In: Czech. Proceedings of the 3th National Conference IBPSA-CZ, Nov. 1-2, 2004, Prague, Czech Republic. pp. 31-36.

[3] Tuohy P. G., Clarke J. A., Johnstone C. Strategies for low carbon buildings. Assessment of design options and the translation of design intent into performance in practice. $\mathrm{PhD}$ thesis. University of Strathclyde. Available at https:// strathprints.strath.ac.uk/46722/.

[4] Rakha T., Rose C. M., Reinhart Ch. F. (2014), A framework for modelling occupancy schedules and local trips based on activity based surveys. ASHRAE/IBPSA-USA
Building Simulation Conference Sep. 10-12, 2014, Atlanta, GA.

[5] Andersen R. V., Toftum J., Andersen K. K., Olesen B. W. (2009), Survey of occupant behaviour and control of indoor environment in Danish dwellings. Energy and Buildings, 41(1), 11-16.

[6] Azar E., Menassa C. C. (2012), A comprehensive analysis of the impact of occupancy parameters in energy simulation of office buildings. Energy and Buildings, 55, 841853.

[7] Flett G., Kelly N. (2016), An occupant-differentiated, higher-order Markov chain method for prediction of domestic occupancy. Energy and Buildings, 125, 219-230.

[8] Andersen F. M., Baldini M., Hansen L. G., Jensen C. L. (2017), Households' hourly electricity consuption and peak demand in Denmark. Applied Energy, 208, 607-619.

[9] Mansouri I., Newborough M., Probert D. (1996), Energy consumption in UK households: Impact of domestic electrical appliances. Applied Energy, 54(3), 211-285.

[10] Patteeuw D., Henze G. P., Helsen L. (2011), Comparison of load shifting incentives for low-energy buildings with heat pumps to attain grid flexibility benefits. Applied Energy, 88(5), 1940-1948.

[11] Love J., et al. (2017), The addition of heat pump electricity load profiles to GB electricity demand: evidence from a heat pump field trial. Applied Energy, 204, 332-342.

[12] Kelly N. J., Tuohy P. G., Hawkes A. D. (2014), Performance assessment of tariff-based air source heat pump load shifting in a UK detached dwelling featuring phase change enhanced buffering. Appl. Therm. Eng., 71(2), 809-820.

[13] Yun G. Y., Tuohy P., Steemers K. (2009), Thermal performance of a naturally ventilated building using a combined algorithm of probabilistic occupant behaviour and deterministic heat and mass balance models. Energy and Buildings, 41(5), 489-499. 